\title{
O DOPS e a repressão política contra militantes comunistas no Estado do Paraná (décadas de 1940 e 1950) ${ }^{1}$
}

\author{
The political and social police (DOPS) and political \\ repression against communists in the State of Paraná, \\ Brazil, during the 1940s and 1950 s
}

\section{Angelo Aparecido Priori² \\ Luciana Regina \\ Pomari $^{3}$}

RESUMO

O objetivo deste artigo é analisar a Delegacia de Ordem Política e Social do Paraná (DOPS/PR) e suas ações no controle e repressão aos comunistas, no Estado do Paraná, nas décadas de 1940 e 1950. Para isso, toma como referência o caso da revolta camponesa de Porecatu e a participação de militantes comunistas nos processos eleitorais na cidade de Londrina

Palavras-chave:: DOPS/PR. Comunistas. Repressão política..

\footnotetext{
1 Pesquisa financiada pela Fundação Araucária/PR.

2 Bolsista de Produtividade da Fundação Araucária. Professor do Programa de Pós-graduação em História da UEM, Maringá/PR, Brasil.

${ }^{3}$ Doutora em História pela Unesp. Professora do Departamento de História da Unespar/Fafipa, Paranavaí/PR.
} 


\section{ABSTRACT}

Current research analyzes the Political and Social Police in the state of Paraná, Brazil, (DOPS/PR) and its activities in the control and repression of communists in the state of Paraná during the 1940s and 1950s. The farmers' revolt in Porecatu and the participation of communists in the election processes in Londrina are taken as references for discussion.

Keyword: DOPS/PR. Communists. Political repression.

\section{Introdução}

Durante todo o século XX, as Delegacias Especializadas de Ordem Política e Social (DOPS) tiveram papel importante no processo de controle e repressão aos movimentos sociais e políticos no Brasil. No Estado do Paraná não foi diferente. Criada oficialmente em $1937^{4}$ e extinta em 1989, o órgão atuou continua e decisivamente para vigiar pessoas, organizações, entidades, partidos políticos e movimentos sociais que de alguma forma pudessem colocar em risco a ordem política e social.

Durante os poucos mais de 50 anos de sua existência, este órgão policial manteve um fichário de anotações de antecedentes político-sociais, cuja importância não é preciso que se faça salientar, dado a importância para os pesquisadores. ${ }^{5}$ Segundo a DOPS, essas anotações eram fundamentais, bem como todos os seus serviços externos, por dizerem respeito às medidas de prevenção, de precaução e de vigilância, visando resguardar a integridade da Nação ou a sua forma de governo contra movimentos subversivos da ordem política e social.

Entre estes movimentos "subversivos da ordem política e social" estavam todas as ações dos militantes comunistas na organização dos trabalhadores rurais em Ligas e Sindicatos, bem como a participação nos processos eleitorais das décadas de 1940 e 1950. É este processo que será tema de análise neste artigo.

As décadas de 1940 e 1950, no Estado do Paraná, foram marcadas pela efervescente organização

\footnotetext{
${ }^{4}$ A DOPS/PR foi criada oficialmente em 15 de março de 1937, pela Lei Estadual n. 177 (DOE, n. 1594, 20 mar. 1937). No entanto, no período anterior, as questões políticas e sociais sofreram controle a cargo de outros organismos policiais, como o Comissariado de Investigação e Segurança Pública na década de 1920; e as Delegacias de Costumes e Segurança Pública ou de Vigilância, Investigação e Capturas na década de 1930. Neste texto faremos referência à DOPS, pois no Paraná era uma Delegacia Especializada.

5 O Arquivo da DOPS/PR foi transferido para o Arquivo Público do Estado do Paraná logo após a extinção do órgão, através do Decreto n. 577/1991, DOE, 11 jul. 1991.
} 
dos trabalhadores rurais, à exemplo do que ocorria em vários estados do País. Nesses vinte anos, alguns movimentos sociais foram significativos e reveladores do grau de insatisfação e miserabilidade em que viviam os trabalhadores do campo. Movimentos como a Guerra de Porecatu (1948-1951), a Revolta do Sudoeste (1957), a organização das Ligas Camponesas e a proliferação dos Sindicatos de Trabalhadores Rurais, para citar os mais significativos, contribuíram para a formação da identidade dos trabalhadores rurais e para colocá-los no campo da política e da história.

A trajetória dos movimentos sociais camponeses que emergiram nas décadas de 1940 e 1950 e todos aqueles que lhes sucederam até hoje, no início do século XXI, representam a mudança de um tempo: do "tempo da inocência" para o "tempo da política" . As palavras de Souza Martins definem a essência desse espírito:

Os pobres da terra, durante séculos excluídos, marginalizados e dominados, têm caminhado em silêncio e depressa no chão dessa longa noite de humilhação e proclamam, no gesto da luta, da resistência, da ruptura, da desobediência, sua nova condição, seu caminho sem volta, sua presença maltrapilha, mas digna, na cena da História (MARTINS, 1989, p. 12).

As pesquisas no campo da história e das ciências sociais sobre os movimentos sociais rurais, no período em tela, revelam dois grandes temas: a luta pela terra e a luta pela legislação social trabalhista. No que tange ao primeiro, é importante frisar que em diversos momentos do século passado essa luta pela terra vai ganhar contornos diferenciados que nos permitem incursionar por caminhos bastante profícuos da análise histórica: movimentos messiânicos, movimentos armados com traços de guerrilha, movimentos sindicais e o movimento dos trabalhadores sem terra são exemplos de como esses agentes sociais rurais, em movimentos de continuidade e rupturas, se articularam na defesa de suas terras ou na luta por novas terras (IOKOI, 1996; MARTINS, 1983).

No que tange ao segundo tema, a luta pela conquista de uma legislação social, vai contribuir para colocar os trabalhadores rurais no debate político brasileiro. É quase consenso na historiografia brasileira dizer que o Estado excluiu os trabalhadores rurais dos benefícios e, também do controle, advindos da lei (SIGAUD, 1979; O' DWYER, 1988; PRIORI, 1996a). Dos benefícios sim. Do controle não, já que ele era exercido pela violência dos jagunços e da policia política, ou ainda pelas "amarras" dos vales de armazéns e barracão.

O debate sobre a da legislação rural só tomou corpo a partir da década de 50, motivado por dois fatores: 1) a atuação de Getúlio Vargas, em seu último mandato, visando estender a legislação social aos homens do campo; 2) os diversos movimentos de camponeses que eclodiram nessa mesma década em todo o país, tais como Ligas Camponesas, revolta armada de posseiros e a proliferação dos Sindicatos de Trabalhadores Rurais. 
Em relação à sindicalização, a preocupação das classes dominantes rurais eram que essas entidades poderiam perturbar a paz social reinante no campo, enveredando-se por um caminho de modificações da estrutura econômica, social e jurídica da sociedade, já que essas entidades seriam passíveis da influência de agitadores profissionais - leia-se aqui a influência dos militantes das Ligas Camponesas e do Partido Comunista Brasileiro (PRIORI, 1996b; SILVA, 2006).

Mas foi a partir desses movimentos e de seus órgãos de representação, que os trabalhadores rurais conquistaram um espaço maior no cenário social, ampliando o debate político acerca de questões fundamentais, como a reforma agrária, a extensão da legislação social trabalhista para o campo, as condições de trabalho e de vida, as relações de trabalho, os preços e a política agrícola.

Essa movimentação, no entanto, chamou a atenção da DOPS para o que estava ocorrendo no campo. Assim sendo, alguns movimentos foram monitorados pela Delegacia com maior ênfase, destacando-se a Revolta Camponesa de Porecatú (1948-1951), movimento armado dos camponeses da região norte do Paraná contra o processo de expulsão de suas terras (PRIORI, 2011); a Revolta Camponesa do Sudoeste (1957), conhecida resistência de colonos e pequenos proprietários contra a violência do Estado e dos jagunços da empresa de colonização CITLA (AMANCIO, 2009); o processo de formação dos Sindicatos de Trabalhadores Rurais (1954-1964), sobretudo aquele tutelado pela ULTAB e pelos militantes do Partido Comunista Brasileiro (PRIORI, 1996b; TONELLA; VILLALOBOS; DIAS, 1999); e em decorrência desse processo de formação dos sindicatos, o espocar de várias greves nas fazendas de café, sobretudo a partir de 1956 (SILVA, 2006).

\section{As primeiras diligências da DOPS}

Tomaremos como exemplo o caso da Revolta Camponesa de Porecatu, para demonstrar como os agentes da DOPS investigaram, classificaram e reprimiram um dos mais importantes movimentos sociais camponeses do século XX.

A revolta camponesa de Porecatu, também chamada de Guerra de Porecatu, ocorreu no Norte do Paraná, no período de 1948-1951. A revolta foi articulada pelo Partido Comunista Brasileiro (PCB) e pelas Ligas Camponesas da região e tinha como objetivo conquistar a posse das terras ocupadas por posseiros, já que as mesmas eram disputadas por grileiros e latifundiários. Com o apoio da polícia e dos jagunços, muitos posseiros tiveram suas posses invadidas e casas e plantações destruídas. Diante da falta de amparo político e legal, resolveram organizar uma resistência armada, com o apoio do PCB. O movimento durou três anos, até que em 1951, foi derrotado pelas forças policiais militares e agentes da DOPS. ${ }^{6}$

Os mecanismos de repressão acionados pelo Estado têm como objetivos centrais manter a ordem

6 Maiores detalhes sobre a revolta camponesa de Porecatu, os leitores encontram em Priori (2011) e Oikawa (2011). 
estabelecida e identificar os "inimigos" do regime. O que pressupõe uma lógica: a do poder. E para isso é fundamental que a repressão, "mesmo quando justificada e reconhecida como necessária pelas autoridades [...] precisa ser traduzida na sua forma legal e tornar-se pública" (ALVES, 1997, p. 7). No entanto, como salienta, ainda, o historiador em tela,

[...] esse lado legal e público da repressão é apenas relativo e aparente. Na verdade, a repressão não se realiza plenamente na sua forma de ser, isto é, a partir de seus fundamentos jurídicos. Ultrapassa-os. Há em toda repressão uma estratégia de ação, uma outra ordem de força, uma outra verdade. Em outros termos, há um projeto político de terror e de construção do medo que objetiva atingir, em primeiro plano, as suas vítimas imediatas e, em segundo, toda a sociedade (ALVES, 1997, p. 7-8).

Pensamos que esses argumentos são úteis para analisar a atuação da DOPS num movimento localizado como o de Porecatu, já que, dificilmente, colocaria em risco o poder central instituído. Ou seja, as estratégias continuavam as mesmas: aqui também foi formulado um projeto político com base no terror e no medo, ou pelo menos na propagação disso, a fim de debilitar a organização dos posseiros que lutavam, de armas na mão, é verdade, para se manterem em suas pequenas posses de terra.

Embora sendo um órgão de controle preventivo das manifestações políticas adversas ao regime instalado, a Delegacia de Ordem Política e Social (DOPS) só começou a fazer diligências na região de Porecatu quando os camponeses estavam bastante organizados e era notável a presença de militantes do Partido Comunista Brasileiro na área. Por que a DOPS chegou tarde à região de Porecatu? Essa pergunta deve ser considerada, já que a Delegacia fazia diligências nas cidades da região Norte do Paraná há vários anos e tinha uma atuação concreta nas cidades há pelo menos 20 anos. Essa atuação tardia se deve ao fato da DOPS não estar preparado para combater movimentos insurrecionais camponeses. Até então a polícia política brasileira não tinha experiência nesse sentido. O fato da vinda para a região do Delegado Eduardo Louzadas da Rocha pode ser um indício: porque o órgão policial iria tirar de São Paulo o seu mais experiente delegado em repressão aos movimentos sociais urbanos e colocá-lo numa região inóspita, onde uma centena de camponeses estava com armas na mão combatendo grileiros e jagunços?

Essa chegada tardia à região é parte da estratégia do órgão em criar condições para o seu trabalho no local. Pode-se afirmar, inclusive, que a estratégia foi bem sucedida, já que num prazo de dez meses o órgão conseguiu acabar com a resistência camponesa armada.

O primeiro relatório produzido pela DOPS sobre Porecatu foi realizado pelo então delegado do órgão, Walfredo de Miranda Assy, em 10 de janeiro de 1951. O documento enfatizava, principalmente, o conflito que estava acontecendo entre o grileiro Jerônimo Inácio da Costa e o posseiro José Billar. Ao descrever esse último, o delegado imprime-lhe a alcunha de "homem que 
cultua idéias bolchevistas" para denominá-lo como um dos principais líderes dos "intrusos" e que não mede esforços para invadir terras alheias e "depredar as benfeitorias existentes" (Arquivo DOPS, pasta n. 1037).

Além desses atributos, o relatório acusava o posseiro José Billar de "desrespeitar a ordem judicial" , já que ele e vários dos seus companheiros se recusavam a ouvir o Oficial de Justiça sobre o mandado de reintegração de posse concedido pelo juiz da comarca de Porecatu em favor de Jerônimo Inácio da Costa.

A presença dos posseiros na região é analisada pelo delegado como preocupante. No entanto, prevendo que o seu relatório serviria de base para "investigações político-sociais" , procura relatar a situação fundiária da região. Diz:

A colonização de terras de Porecatu, Jaguapitã, Centenário, Guarací e localidades vizinhas, não estão sendo feitas pelo antigo plano, isto é, em pequenos sítios e sim em grandes fazendas. Não nos cabe aqui, comentar esse plano, e, acreditamos, não é isto preciso. Assim, dada a exuberância do solo e o afluxo de pessoas vindas de outros estados, a procura de terra é grande. Sobem vertiginosamente os preços. Alguns colonos, encontrando terras sem administração, pensando ser devolutas, ali constróem suas casas. Esse número de pessoas mais ou menos bem intencionadas, é pequeno (Arquivo DOPS, pasta n. 1037).

Se o número de posseiros "bem intencionados" é muito pequeno, quem, para o delegado da DOPS, são esses homens e mulheres que acorreram à região? "Malandros" , essa foi a definição mais pura e direta do relatório. Para o delegado, esses "malandros" eram pessoas que vinham de outros estados, entravam nas fazendas arbitrariamente e ali se instalavam, fazendo pequenas plantações ou construindo simples choupana para moradia, com o objetivo de mais tarde "obter grossa indenização" . E uma vez indenizados pelos "verdadeiros" proprietários, "saem e vão intrusar outras fazendas" num verdadeiro comércio ilícito e altamente lucrativo - argumentava.

O relatório narra ainda que na região havia muita "propaganda bolchevista" , tais como boletins subversivos, jornais e folhetos. No entanto, a maior preocupação do delegado da DOPS foi a constatação de que, a partir de Presidente Prudente, adentrava na região "grande quantidade" de armamentos e munições. Segundo o relatório, essas armas chegavam com facilidade na área conflituosa devido a atuação da Delegacia Regional de Presidente Prudente, através de seu delegado, que não exercia o "necessário controle na venda de armas, explosivos e munições" , contribuindo assim para o acirramento da violência no campo.

Como não poderia deixar de ser em um relatório como esse, o delegado da DOPS atenta o seu olhar, sobretudo para as possíveis lideranças camponesas da região e para a atuação do Partido Comunista Brasileiro (PCB). E ao identificar alguns líderes, principalmente José Billar, Hilário 
Gonçalves Pinha e José Ribeiro, argumentava que eles faziam parte de uma bem arquitetada campanha de infiltração comunista na região, que visava, sobretudo, menosprezar as autoridades constituídas, armar os posseiros e distribuir propaganda subversiva. A preocupação com o PCB não só era grande, como o agente imaginava que o partido tinha um plano muito bem estabelecido para desencadear na região uma guerra de guerrilha, pois, segundo o relatório:

o progresso sucessivo do mal, o entrelaçamento e a coordenação dos movimentos, as fugas e emboscadas bem organizadas, as trincheiras de modo militar encontradas, são outras tantas provas do comando bolchevista. Esses indivíduos, que a princípio tinham o nome de posseiros, passaram a ser chamados intrusos, mais tarde assassinos e tocaieiros, e, para, na fase final que devemos evitar, receber o nome de GUERRILHEIROS. Este é, segundo cremos, o quadro esquemático do PCB (Arquivo DOPS, pasta n. 1037).

Mesmo fazendo essas considerações, o agente da DOPS alertava seus superiores que a situação de conflitos agrários que reinava na região não foi criada pelo $P C B$, mas pelos desmandos e desvios nas sucessivas políticas voltadas para a colonização da região. No entanto, enfatizava, "o PCB, é verdade, não criou a situação, mas, não menos verdade é que, aproveitando-se dela, incentivou-a, aumentou-a, coordenou e bolchevisou os intrusos" (Arquivo DOPS, pasta n. 1037).

Em outro longo relatório sobre a região, o delegado Eduardo Louzadas da Rocha enfatizava, no mesmo sentido:

Relativamente ao caso de Porecatu, seja-nos lícito acrescentar, conforme já foi dito em peças anteriores, ter sido ele originário de erros, promessas demagógicas e desnecessária violências que, cometidas no passado, geraram uma atmosfera de desentendimento, revolta e agitação, habilmente encampada e explorada pelo Partido Comunista, sob a orientação suprema de sua direção nacional e através de três principais instrumentos: o comitê de zona de Londrina, quadro intermediário que mantinha a direção imediata; "Machado" , elemento de ligação do Comitê de Zona com a direção local; e Celso Cabral de Melo, enviado especial da direção nacional, que mantinha o comando e a direção imediata dos acontecimentos, recebendo instruções do Comitê de Zona, através do agente de ligação "Machado" (Arquivo DOPS, pasta n. 599).

Como se percebe por esses dois relatórios, a principal preocupação da DOPS era efetivamente com a presença de militantes do Partido Comunista na organização do movimento armado de Porecatu. Para isso, fazia-se necessário montar uma estratégia que viesse reduzir os grupos armados para o mínimo possível, restritos apenas àqueles que se entregavam, "por convicções 
comunistas" , às atividades subversivas.

\section{Desarticulando o núcleo da resistência: a cidade de Londrina}

Seguindo essa estratégia, o primeiro local que deveria se atacar era o núcleo pensante de tal movimento. E ele estava concentrado, sobretudo, na cidade de Londrina, articulado politicamente pela Direção Zonal do Partido, supervisionado pelo Comitê Estadual e pelo Comitê Central.

Londrina, a principal cidade do interior do Paraná, sempre foi muito bem vigiada pela DOPS. Há nos arquivos, centenas de pastas com relatórios e documentos relativos às diligências realizadas na cidade durante a existência da Delegacia. Pelo menos desde a década de 1930 existem relatórios. Mas foi a partir de 1945, quando o PCB começou a ter uma presença mais forte na cidade $^{7}$, que aumentou consideravelmente os relatórios sobre a cidade, com um pico importante no período 1950-1964 e 1968-1975.

O aumento das atividades de controle da DOPS nas décadas de 1940 e 1950 se deveu basicamente sobre a participação do PCB na organização dos movimentos sociais no campo e em campanhas eleitorais. A revolta de Porecatu e a articulação do Sindicato dos Trabalhadores Rurais tiveram um acompanhamento mais direto com desdobramentos de caráter criminal. ${ }^{8}$

Londrina vai exercer um papel importante na organização do movimento de camponeses do Norte do Paraná, pois é nessa cidade que se situavam a direção intelectual e as pessoas que elaboravam tecnicamente a execução do projeto da resistência armada de Porecatu. Foi em Londrina que se realizaram os plenos de trabalho; ali também, em gráficas clandestinas, eram impressos os jornais, os boletins e os folders de agitação distribuídos na região e na área conflagrada.

As diligências e atividades dos agentes da DOPS na cidade de Londrina foram no sentido de localizar e identificar os dirigentes do Comitê Municipal do PCB. No entanto, mais do que a simples identificação o órgão de repressão tratou rapidamente de abrir um inquérito policial objetivando responsabilizar os dirigentes de Londrina pelo apoio logístico e político aos camponeses de Porecatu na sua luta pela manutenção da posse da terra (trata-se do processo 109/51). Embora um inquérito policial não fosse suficiente para prender os dirigentes locais do PCB, os agentes da DOPS procuraram outros mecanismos que pudessem surtir um efeito razoável.

\footnotetext{
7 Sobre o comunismo em Londrina, bem como a repressão da DOPS, ver o trabalho de Sônia Adum (2003).

8 Durante esse período foram instalados diversos processos crimes contra militantes do Partido Comunista na cidade. Entre eles podemos destacar o Processo 109/51 e o 6094/56. O processo 109/51, que detalha a participação e as atividades do PCB na organização do movimento de Porecatu foi analisado por Sônia Adum (2003). O processo 6094/56 foi analisado por Priori (1996a).
} 
E essa possibilidade veio com as eleições municipais, marcada para o dia 22 de julho de 1951, em todos os municípios do Estado.

Como sempre foi praxe, durante o período que estava na ilegalidade, o PCB procurava inserir seus quadros em partidos legais com o objetivo de disputar as eleições dentro das regras definidas pela Justiça Eleitoral e assim, livremente, poder se aproximar das massas e fazer o seu trabalho de proselitismo político, agitação e propaganda. Em Londrina, no ano de 1951, os comunistas se alojaram nas hostes do Partido Trabalhista Nacional (PTN), tendo inclusive o controle da direção municipal de tal legenda. Para se ter uma idéia, o diretório municipal do PTN quase que se confundia com a direção do Comitê Zonal do PCB. Com isso puderam lançar diversos candidatos a vereadores, além de apoiar uma candidatura a prefeito, simpática ao PCB.

Registrada as candidaturas, o PCB tratou logo de colocar os militantes e simpatizantes para fazer proselitismo nas ruas, tendo como slogan de campanha a frase, por sinal bem apropriada para a época: "pela paz e contra a carestia" . A propaganda eleitoral era realizada através de distribuição de boletins, inscrições em muros, reuniões em bairros urbanos e em núcleos agrícolas da região, além dos tradicionais comícios.

O primeiro comício realizado pelo PCB de Londrina na campanha eleitoral daquele ano ocorreu em 13 de junho, na praça Rocha Pombo. Segundo relatório da DOPS, o evento foi um "autêntico comício de agitação comunista, cujos temas giraram em torno da campanha da paz, da guerra da Coréia, da Conferência Pan-americana de maio, 'onde Getúlio e João Neves venderam o Brasil aos americanos' , a carestia, a entrega da terra aos que nela trabalham" (Arquivo DOPS, pasta n. 599).

O comício, mesmo tendo como objetivo central divulgar as candidaturas de militantes do PCB/PTN à câmara de vereadores acabou se transformando num evento de contestação das políticas sociais do governo e da realidade internacional. É evidente que isso fazia parte da estratégia do PCB em prática naquele momento. No entanto, nada chamou mais atenção, pelo menos aos "arapongas" de plantão, do que os discursos pelo fim do latifúndio, pela reforma agrária e pela solidariedade com a resistência camponesa de Porecatu.

Ao que parece esse comício do dia 13 foi realizado com pleno êxito. Tanto que motivou o PCB/PTN a realizar, no dia seguinte, na Vila Casoni (bairro de Londrina, majoritariamente operário) um novo comício. No entanto, esse ato não foi realizado, devido à proibição da Polícia Civil. ${ }^{9}$ Impedidos de realizar tal manifestação, o PCB/PTN tratou de evocar a Justiça Eleitoral e a legalidade de suas candidaturas a vereador para que a mesma garantisse a realização dos comícios. O partido então, desafiando a polícia, marcou nova manifestação para o dia 17 de junho, informando que o comício seria realizado "de qualquer forma" .

\footnotetext{
${ }^{9}$ A polícia já havia tentando impedir o comício do dia 10 de junho, mas o mesmo foi realizado com a autorização da Justiça Eleitoral.
} 
A atitude do PCB/PTN, de desafiar a polícia, fez que essa radicalizasse seus métodos de atuação, armando um plano para prender toda a direção do Partido na cidade de Londrina, o que veio a ocorrer na madrugada do dia 17 de junho de 1951. Conforme escreveu o Delegado da DOPS que atuou no Norte do Paraná:

Esse incidente é relatado para se explicar porque foi que necessitamos precipitar a ação policial, com a prisão nesse mesmo dia 17 dos principais dirigentes comunistas locais. Do balanço a que se precedeu naquele momento, entendeu-se que seria proveitoso correr os riscos dos inconvenientes dessa precipitação, atalhando, porém, no nascedouro, a perigosa onda de agitação que os dirigentes de Londrina tentavam deflagrar sob pretexto de propaganda eleitoral. São inegáveis os prejuízos que dessa precipitação necessária resultaram para a posterior ação junto aos bandos armados de Porecatú; mas são igualmente visíveis os benefícios dessa decapitação inicial de atividades que prometiam criar em Londrina ambiente de inegável dificuldade para aquela mesma ação policial (Arquivo DOPS, pasta n. 599).

Foram presas naquela madrugada do dia 17 de junho as seguintes pessoas: Flávio Ribeiro, Newton Câmara, Almo Saturnino, Milcíades Pereira da Silva, Helena Pereira da Silva, Bento Paiva, Lázara Araújo Paiva, Manoel Jacinto Corrêa e Gerson Monteiro de Lima, todos integrantes e dirigentes do Comitê de Zona do PCB no Norte do Paraná, com sede em Londrina.

A prisão desses militantes comunistas foi motivada pela intenção de desrespeitar uma ordem policial que impedia a realização de um comício eleitoral do PCB/PTN. No entanto, o que de fato estava em jogo e que devia ser desarticulada era a direção intelectual e política da resistência dos posseiros de Porecatu e a assistência material aos resistentes, como o fornecimento de roupas, alimentos e financiamento dos grupos armados na floresta.

Ao fazer o pedido de prisão preventiva ao juiz da $2^{a}$. Vara Criminal do Fórum da Comarca de Londrina, o delegado Celso Nicolau dos Santos afirmava que esses dirigentes eram os mentores de menor grau na hierarquia do PCB e que, portanto, recebiam ordens diretas do Comitê Central do Partido, para organizar a ação armada em Porecatu, Jaguapitã e Centenário.

$\mathrm{Na}$ residência de cada um desses indiciados foi apreendido farto material subversivo: são documentos, manifestos, boletins, volantes, em que abertamente se pregam a revolução, a conquista armada do poder, a instituição de uma "democracia popular" (a exemplo do que os dirigentes de Moscou impuseram aos países ocupados da Europa Central), a mobilização de um exército popular e o desacato e a afronta às autoridades (Arquivo DOPS, pasta n. 599). 
Além dessas constatações, os dirigentes eram acusados de explorar a ignorância e a boa fé dos trabalhadores agrícolas da região, procurando articulá-los em "Ligas Camponesas" , transformando-os em bandos armados a serviço do Partido Comunista e da violência rural.

O juiz da 2a Vara Criminal acatou o pedido do delegado e decretou a prisão preventiva dos acusados no dia 26 de junho de 1951. Assim mesmo, quando tal decreto foi expedido, os acusados já haviam sido presos por um contingente policial sob a supervisão da DOPS e se encontravam em local ignorado, fato que ocorreu por pelo menos uma semana. Foi somente no dia 02 de julho daquele ano que os acusados foram recolhidos à prisão provisória da cidade.

A prisão e a manutenção de presos em local ignorado (ou seja, a prática do sequestro) sempre eram recorrentes nas atividades da DOPS. Durante o período que os 9 presos ficaram em poder daquela Delegacia de repressão, eles estiveram em diversos locais, sendo que um grupo ficou preso na cidade de São Sebastião da Amoreira e outro em Assaí, até serem devolvidos para a cadeia pública de Londrina (JORNAL A TARDE, 02 jul. 1951). Como vimos acima, além dos sete homens também foram presas duas mulheres: Helena Pereira da Silva e Lázara Araújo Paiva.

Quando a prisão foi "legalizada" e os presos recolhidos à cadeia pública, as duas mulheres foram separadas do grupo e internadas em uma Casa de Saúde para reabilitação e tratamento. ${ }^{10}$ No dia 10 de julho de 1951, o promotor da Comarca de Londrina ofereceu denúncia criminal contra os acusados por "atos subversivos" e "atividades contra a segurança nacional" , relaxando a prisão apenas de um acusado, o médico Newton Câmara, que foi posto em liberdade no mesmo dia. ${ }^{11}$

As atividades da DOPS em Londrina não se resumiam apenas em acusar os participantes da direção do Comitê Municipal do PCB ou do PTN. Ademais, o órgão investigava atividades de pessoas ligadas ao meio político tradicional da cidade e personalidades que pudessem ter algum vínculo com os camponeses de Porecatu. É o caso, por exemplo, do senhor Milton Ribeiro de Menezes, na época candidato à prefeitura de Londrina, depois eleito. Ele teve a sua vida investigada pelos agentes da Polícia Política. Milton Menezes era acusado de ter participado de atividades "caracteristicamente comunistas" , conforme enfatizou o tenente coronel Albino Silva, chefe de Polícia do Estado, em carta encaminhada ao governador do Estado (Arquivo DOPS, pasta

\footnotetext{
10 Não foi possível identificar os motivos da internação das mulheres em uma casa de Saúde. A Cadeia Pública de Londrina, nessa época, já recebia mulheres presidiárias. Pode-se levantar a hipótese de que a polícia tentava, com esse ato, descaracterizar a militância política e comunista dessas mulheres, procurando mostrar que as mesmas não gozavam de sadias faculdades emocionais. Ou ao contrário, elas realmente estavam debilitadas física e emocionalmente e por isso foram internadas numa casa de Saúde. Sobre a atuação da Polícia na cidade de Londrina, durante os anos 1950, recomendamos a leitura de Rolim (2008).

${ }^{11} \mathrm{O}$ delegado do DOPS Eduardo Louzadas Rocha, ao saber do relaxamento da prisão de Newton Câmara protestou, pois segundo ele, "o Dr. Newton Câmara constituía um dos principais responsáveis pelos acontecimentos, é conhecido, reconhecido e proclamado como o dirigente máximo do comunismo na zona [norte do Paraná]" (ARQUIVO DOPS, pasta n. 599).
} 
n. 599). E para provar que o então candidato a prefeito tinha ligação com o PCB o chefe de polícia apresentou vários indícios:

\begin{abstract}
a) - certidão de uma anotação de antecedentes políticos e sociais, datada de 28 de julho de 1946, por onde se vê que o Dr. Milton Menezes tomou parte da sessão de instalação oficial do Partido Comunista Brasileiro, na cidade de Londrina, ocasião em que se fez fotografar na companhia de outros chefes comunistas, alguns dos quais ainda agora seriamente comprometidos nos acontecimentos subversivos do Norte do Estado.
\end{abstract}

b) - reprodução da fotografia do Grupo Fundador do PCB em Londrina;

c) - Lista de contribuições, sem indicação de data, onde entre outros nomes figura o de MILTON RIBEIRO MENEZES;

d) - Cópia de uma ata de reunião da "Célula Siqueira Campos" , realizada em 11 de setembro de 1946;

e) - O documento no. 7 é grandemente expressivo e não pode sofrer contestação. Trata-se de uma lista de ajuda financeira ao Conselho da Paz de Londrina, onde, entre a assinatura de Flávio Ribeiro, notório líder comunista e a indicação dos nomes de Manoel (Manoel Jacinto Corrêa) e de Gerson (Gerson Monteiro de Lima), ambos também notórios líderes comunistas, aparece o autógrafo de Milton Ribeiro Menezes, autenticado, de modo insofismável, o seu papel de contribuinte da campanha de ajuda financeira ao Conselho da Paz de Londrina (Arquivo DOPS, pasta 599).

No entanto, mesmo tendo toda esta extensa ficha, o governador do Estado, Bento Munhoz da Rocha Neto determinou, a partir de um pedido do próprio Milton Ribeiro Menezes, que as anotações em sua ficha na DOPS fossem canceladas. Essa atitude do governador gerou um mal estar dentro do órgão e protesto do Chefe de Polícia, que dizia que aquela Delegacia Especializada não só tinha razões de fazer tais anotações como a obrigação de ampliá-las, já que o investigado tratava-se de um

[...] indivíduo estreitamente ligado a inimigos declarados do regime, solermente infiltrados em correntes democráticas com o propósito de conquistar a direção política e administrativa do Município de mais importância econômica de nosso Estado, e que não trepida em se travestir de cordeiro para alcançar esse objetivo.

E adiantava, ainda: 
Registrar em seus arquivos a co-participação em atividades contrárias ao regime, é a mínima das sanções que pode a Polícia do Estado fazer recair sobre quem, como Milton Ribeiro de Menezes, em que pesem as aparências mentirosas e sua desenvolta capacidade de dissimular, está inegavelmente ligado ao criminoso "Comitê Comunista de Londrina" (Arquivo DOPS, pasta n. 2763).

É oportuno abrir aqui um parêntese para melhor esclarecer essa exposição e deixar claro que são pronunciamentos de agentes da polícia política. Portanto, eles devem ser analisados com muito cuidado. As anotações do DOPS nem sempre se revestem do caráter de provas capazes de produzirem a convicção da culpa daqueles a que se referem; é normal que muitas vezes contenham apenas indicações de caráter informativo, necessárias, entretanto, para o estabelecimento da incidência do trabalho vigilante e preventivo de uma Delegacia de Ordem Política e Social, como é o caso da DOPS. No caso em tela, a ficha de anotações de Milton Ribeiro Menezes, cujo cancelamento ele solicitou e obteve do governador, continha apenas dados informativos, comum naquele órgão.

A prisão dos dirigentes do PCB em Londrina foi encarada pela DOPS como o primeiro passo para desmontar a revolta armada dos posseiros de Porecatu. Com a abertura do Inquérito e o recolhimento daqueles militantes à prisão - escreveu o Delegado da DOPS, Eduardo Louzadas da Rocha - "foi possível dedicar especial carinho à outra parte do problema, que era o que se poderia dizer o aspecto de execução, constituído pelos bandos armados de Porecatu" (Arquivo DOPS, pasta n. 599).

$\mathrm{Na}$ ação policial do dia 17 de junho, realizada na cidade de Londrina, foram presas mais duas pessoas, que até aquele momento eram desconhecidas pelos agentes da DOPS. Tratavam-se de Alberto Manoel, "elemento perigoso" e de Pedro Ferreira da Silva, posteriormente identificado como Celso Cabral de Melo, "um dos principais elementos da ação criminosa" , sempre nas palavras dos agentes policiais. Os dois desconhecidos da DOPS foram enquadrados em um Inquérito Policial específico, já que ambos, por estarem mais ligados à ação local na floresta, "foram reservados para o inquérito em torno dos fatos que propriamente constituíram atividades a serem julgadas na Comarca de Porecatu" (Arquivo DOPS, pasta n. 599).

As prisões de Londrina tiveram um natural reflexo nas atividades da revolta armada em andamento na região de Porecatu, principalmente no moral dos componentes dos grupos armados. Não tanto, obviamente, pela prisão dos dirigentes do PCB de Londrina, já que eles não tinham uma aproximação mais direta com os posseiros, mas sobretudo pela prisão inesperada de Celso Cabral de Melo, ex-dirigente nacional do PCB e especialmente enviado pelo Partido para aquela região. Celso Cabral era o homem do Partido encarregado de dar direção política e organizar os grupos armados. A sua prisão, de certa forma, acarretou alguma desorientação nesse sentido. Não que os posseiros não tivessem outras lideranças. Elas existiam e tinham um poder fundamental no processo de luta, já que eram lideranças forjadas entre os próprios posseiros, 
como "Itagiba" (Hilário Gonçalves Pinha) e "Strogoff" (Arildo Gajardoni), que na hierarquia da revolta vinham abaixo apenas do capitão "Carlos". No entanto, nem "Itagiba" nem "Strogoff" tinham a mesma autonomia de "Carlos", além deste último ser o homem de ligação entre os posseiros armados e a direção do Partido Comunista.

Mas o que provocou um maior estrago nas atividades dos posseiros, com certeza foi a atitude do capitão "Carlos" depois de sua prisão. Nos seus depoimentos à polícia, ele abriu a boca, informando todas as ações programadas, a quantidade de armas, o pessoal rebelado dentro das matas, facilitando a ação da polícia no desbaratamento da revolta armada.

\section{As ações da DOPS em Porecatu}

Em meados do mês de junho de 1951, o chefe de Polícia do Estado do Paraná, tenente coronel Albino Silva, entrou em contanto com o Departamento de Ordem Política e Social (DEOPS) do Estado de São Paulo e convidou para dirigir o trabalho da polícia na região de Porecatu, Eduardo Louzadas Rocha, delegado especializado em atividades de esquerda na capital paulista. Ao chegar ao Paraná, o Dr. Louzada, como era chamado, recebeu todas as informações e relatórios produzidos pela polícia sobre o Norte do Paraná, além de amplos poderes (ele só estava abaixo do Chefe da Polícia do Estado do Paraná) sobre as polícias militar e civil para tentar acabar com a revolta camponesa.

O Delegado Eduardo Louzadas Rocha tinha uma grande experiência em conflitos sociais, sobretudo urbanos, mas no caso de Porecatu também mostrou bastante eficiência, já que armou uma estratégia que desbaratou a revolta em pouco mais de dois meses.

As prisões dos dirigentes do Comitê do PCB em Londrina e de Celso Cabral de Melo, aliada à ampliação do número de soldados do Exército e da Polícia Militar do Estado, provocaram um refluxo quase que imediato no movimento. Muitos dos posseiros que integravam os grupos armados acabaram abandonando o movimento e, alguns deles, tornaram-se informantes dos agentes da Delegacia de Ordem Política e Social. Os agentes da DOPS avaliavam que os posseiros, por serem "roceiros simples, analfabetos e desorientados", integravam os grupos armados apenas porque o PCB os haviam recrutados através das "mais falaciosas promessas". E que nesse sentido deveriam realizar um trabalho contrário de "catequese", visando reduzir os grupos armados apenas às "proporções restritas, representada pelo pequeno número dos que se entregavam, por convicção comunistas, às atividades subversivas que o grupo desenvolvia" (Arquivo DOPS, pasta n. 599).

É certo que nesse trabalho de informação, os delegados da DOPS tinham muitas dúvidas. Uma das principais era o de precisar quantos posseiros efetivamente estavam organizados e em armas. Nas diligências iniciais, relatórios daquela Delegacia apontavam, ora 500, ora 300 elementos armados 
dentro da floresta. Quando da última investida da força policial, a partir de junho de 1951, foi que os agentes aquele órgão repressor perceberam que dentro das matas não existiam mais do que 100 homens organizados em grupos armados. Essas imprecisões acabavam confundindo os agentes e superestimando a ação dos posseiros, aliás muito bem montada, conforme reconhece o delegado Eduardo Louzadas da Rocha.

\begin{abstract}
A esse erro fomos levados de um lado pelo natural exagero e pela natural fantasia de informantes atemorizados e de outro lado por um curioso expediente da direção dos bandos que, nas diferentes sortidas em que mantiveram contato com os informantes, nos vários atos de violência seguidamente praticados, dividiam os componentes do bando em dois grupos, um deles fora da mata, nas estradas, nas derrubadas e nas sedes, enquanto outro grupo, bem mais reduzido, ocupava o orla da mata, de arma em punho, e era referido pelos que saíam como sendo centenas de homens (Arquivo DOPS, pasta n. 599).
\end{abstract}

Uma segunda dúvida era a procedência e a quantidade das armas. Os "arapongas" da DOPS alegavam que os posseiros tinham, com certeza, duas metralhadoras, granadas de mão, um mosquetão de cavalaria, diversas carabinas e rifles, além de pistolas de guerra e revólveres comuns. "Apesar desse armamento não ter sido apreendido e não ter sido possível identificar a sua procedência pelo menos a munição se encontra à disposição da Justiça Pública da Comarca de Porecatu" , escreveu o delegado Eduardo Louzadas se justificando por não ter conseguido desbaratar esse problema (Arquivo DOPS, pasta n. 599).

Na realidade, os agentes da DOPS tinham desconfiança de que as armas vinham do Estado de São Paulo, já que em um primeiro relatório, um agente atentava para a necessidade de coibir a venda de armas "que se dava livremente e com facilidade" na região Oeste de São Paulo, principalmente na cidade de Presidente Prudente (Arquivo DOPS, pasta n. 1037).

A prisão de Celso Cabral de Mello, ao que parece, teve peso decisivo no desmantelamento da resistência armada. Em seus depoimentos para o Inquérito Policial instaurado logo após a sua queda ele revela fatos sobre os quais até então a Força Pública e os delegados da DOPS tinham dúvidas. Num primeiro momento ele fala da composição dos grupos e da quantidade de pessoas com armas na mão:

Os bandos, ultimamente, estavam assim organizados: cerca de dez homens no acampamento de Padilha, chefiado por Arildo Gajardoni e sete homens com o declarante, no acampamento José Billar. No total o grupo se compunha de cerca de vinte homens, tendo havido diversas deserções. 
Num segundo momento, relaciona as armas em poder dos resistentes.

Duas submetralhadoras, seis granadas de mão, doze carabinas, a metade da qual em mau estado de funcionamento, três ou quatro pistolas Parabellum, uma pistola colt 45, do uso de Arildo, um mosquetão, sessenta cartuchos de metralhadora 9 $\mathrm{mm}$, cerca de trezentos cartuchos para a metralhadora 45 , cerca de 400 cartuchos para o mosquetão, cerca de oitocentos tiros munição 44, uma carga para cada pistola e cerca de sessenta tiros para revólver. Acredito que essa munição não tenha sido renovada, porque ultimamente os bandos já vinham encontrando muitas dificuldades para adquirir munição (Arquivo DOPS, pasta n. 599).

Com esse depoimento, Celso Cabral de Melo revelou os pontos mais fracos e débeis do movimento. Era fato corrente, e a polícia militar, os agentes da DOPS, a imprensa e até mesmo a população local faziam ênfase, de que os grupos armados na floresta eram numerosos e estavam dotados de armamentos pesados e muita munição.

O próprio delegado especial da DOPS, Eduardo Louzada, reconheceu que eles imaginavam um movimento com um número muito maior de membros. Relatando o depoimento de Celso Cabral de Mello ao chefe da Polícia do Paraná, disse:

As informações preliminares que obtivemos sobre a organização, a constituição, o sediamento e o equipamento dos bandos armados, confirmaram quase que "in totum" . As informações mais ou menos imprecisas que obtivemos a respeito do seu número é que sofreram apreciável redução, pois os informantes faziam referência ora 500, ora a 300 elementos, quando na verdade talvez não chegassem a 100. A esse erro fomos levados de um lado pelo natural exagero e pela natural fantasia de informantes atemorizados e de outro lado por um curioso expediente da direção dos bandos, que nas diferentes sortidas em que mantiveram contato com os informantes, nos vários atos de violência seguidamente praticados, dividiam os componentes dos bandos em dois grupos, um deles fora da mata, nas estradas, nas derrubadas e nas sédes, enquanto outro grupo, bem mais reduzido, ocupava a orla da mata, de arma em punho, e eram referidos pelos que saiam como centenas de homens (Arquivo DOPS, pasta n. 599).

Essa atitude de Celso Cabral de Mello foi considerada pelos posseiros como alta traição ao movimento. Hilário Gonçalves Pinha, um dos comandantes da revolta e Manoel Jacinto Corrêa, importante membro da direção zonal do PCB e um dos mais influentes colaboradores da resistência foram taxativos na afirmação.

Em 1985, em entrevista à Folha de Londrina, Hilário Gonçalves Pinha falou do "capitão Carlos" 
com certa mágoa:

[...] veio para dar aulas de guerrilhas, auto-defesa, de explosivos e para fazer a ligação do campo com a cidade. Mas o Celso caiu e deu todo o serviço: denunciou os companheiros que estavam na mata lutando, entregou quem eram os responsáveis pelos grupos, que armamentos usavam, tudo (Folha de Londrina, 23 jul. 1985, p. 17).

No entanto, em depoimento mais recente desvela pesadas críticas ao seu antigo comandante:

Ele fazia o contato e ficava uns dias só no mato. Ele foi um traidor. Ele não tinha direito de abrir o jogo. Porque até a prisão desse cara, o poder, a reação, o poder de repressão achava que a gente era um batalhão, eles falavam em 300, 500 homens. Mas nós não passávamos de 25 nunca. Com a arma na mão não passamos de 25. Mas depois que eles tiveram essa informação caíram com tudo, para ocupar a região (Pinha, 7 out. 1999).

Já o militante do Partido Comunista, Manoel Jacinto Corrêa, é mais enfático quando se lembra do membro do Comitê Central enviado à área. Segundo o depoente, além do "capitão Carlos" delatar os posseiros, ele abandonava as suas tarefas no mato e vinha para os prostíbulos de Londrina gastar todo o dinheiro adquirido com tanto sacrifício para alimentar a luta. "Ele se julgava acima de todos nós, dirigentes do PCB na região e a mim, particularmente, chamava de 'caboclo provinciano', por causa das minhas exigências com as coisas" (Folha de Londrina, 26 jul. 1985; CORREA, 1983).

A delação dos companheiros, feita pelo seu maior dirigente, abriu o caminho para a DOPS e a Polícia Militar fecharem o cerco contra os posseiros e desmobilizar o movimento. Obviamente, essa não foi uma tarefa fácil. Foi necessária uma grande operação militar para que a vontade da repressão fosse colocada em prática.

\section{A operação limpeza}

Com informações mais confiáveis sobre a quantidade de pessoas na floresta, a quantidade de armas, o poder de munição e o conhecimento do moral dos posseiros rebelados, a polícia militar e os agentes da DOPS montaram uma estrutura para fazer uma varredura na região, visando prender os posseiros revoltados e debelar de vez o movimento armado.

Para isso reforçaram os seus contingentes. A cada dia mais tropas eram deslocadas para a região. No dia 20 de junho, por exemplo, duas aeronaves da empresa Aerovias Brasil desceram no 
Aeroporto de Londrina trazendo dois batalhões da Força Policial do Estado. ${ }^{12} \mathrm{Na}$ noite desse mesmo dia, os contingentes seguiram para a região conflagrada para se juntar aos demais. Com as tropas, vieram mais quinze agentes da DOPS para reforçar o trabalho de investigação. A própria Força Aérea Brasileira (FAB) deslocou para Londrina uma esquadrilha de aviões de combate para ficar à disposição das autoridades, e caso fosse necessário, "auxiliar na ação policial" (A Tarde, 22 jun. 1951).

O governo do Estado de São Paulo também deslocou tropas para vigiar a sua fronteira, visando impedir uma debandada dos posseiros rebelados para aquele Estado (Gazeta do Povo, 28 jun. 1951). Antigos moradores da região disseram para o jornal Folha de Londrina que havia tropas estacionadas nas cidades da região, como Presidente Prudente e Iepê e nos portos do Rio Paranapanema, como Marcondes, Itaparica e Afonso Camargo, além de estradas serem cotidianamente vigiadas (FELISMINO, 1985). Com essa estrutura montada, ficou mais fácil começar a operação "limpeza" .

Para os posseiros a situação se tornava cada hora mais difícil. Os remanescentes dos grupos armados continuavam embrenhados na floresta, impedidos de se locomoverem, já que todo o Norte do Paraná estava tomado por contingentes policiais e agentes da DOPS. O fato de não poderem se encontrar com suas famílias e saber como estavam suas posses agudizou ainda mais a crise interna do movimento. Assim, começaram as deserções dos posseiros, abandonando a luta armada, ou o que era pior, como no caso de alguns, que tornaram-se informantes da DOPS. Foi o caso de Mário Verone, que se entregou à polícia e dois dias depois já estava trabalhando como informante, encarregando-se, inclusive, de levar o destacamento militar até o acampamento perto de Colorado, onde estava "Strogoff" e "Itagiba" . As deserções e o cerco da polícia colocavam o movimento num declínio irreversível. A deserção fazia parte das estratégias dos delegados da DOPS de reduzir os grupos armados apenas aos militantes declarados do PCB. Aquele posseiro que fosse convencido pela DOPS para abandonar a luta armada e passar a ser informante seria retirado do processo criminal instalado, além de receber um lote de terras na região de Paranavaí (Arquivo DOPS, pasta n. 599).

Durante a fase da limpeza, muitos trabalhadores foram presos. Qualquer suspeito era recolhido à cadeia para depoimento. A maioria acabava ficando apenas dois ou três dias e depois eram libertados. Nas fontes que analisamos conseguimos catalogar 23 prisões, ocorridas durante os meses de junho e de julho de 1951. É bem provável que tenha sido maior o número de presos. ${ }^{13}$

12 Conforme registram notícias dos jornais O Dia (22 jun. 1951), Diário da Tarde (22 jun. 1951) e Gazeta do Povo (23 jun. 1951).

13 Foram presos nas ações de junho e julho, os seguintes posseiros: Antônio Camilo, José Vitorino Alves, José Pereira Leite, Alfredo Dionísio Neto, José Manoel da Silva, Domingos Palhares, Benevilde Carvalho de Oliveira, Alcides Ferreira da Silva, Antônio de Souza Santos, José Francisco da Silva, Lino Moreira dos Santos, João Antônio da Silva, José Soares dos Santos, João Leite, José Veroni, Pedro Ferreira da Silva, Alberto Manoel, José Franco de Souza, Mário Veroni, Germano Arnold, Lázaro Bueno Camargo, Orozimbo Vieira de Moraes e João Luiz de Oliveira (Arquivo DOPS, pasta n. 599). 
Os principais remanescentes dos grupos armados - que neste período somavam pouco mais de uma dezena - ainda continuaram juntos por algum tempo. O passo final para a dispersão ocorreu com a libertação dos dirigentes comunistas de Londrina, meses depois de terem sido presos. Soltos, eles foram à antiga zona da "revolta" para sepultar de vez o que havia sobrado do "embrião revolucionário" . As armas foram recolhidas e cada um dos integrantes que resistiram ao cerco policial, ou pelo menos que não foram localizados pela polícia, seguiram seu destino, partindo em direção a outras regiões do estado do Paraná, São Paulo e Goiás. Muitos desapareceram para nunca mais serem vistos.

A ação policial mostrou-se bastante eficaz. Tanto pela violência utilizada na fase inicial dos conflitos, bem como pelo intenso processo de varredura, empregado em toda a região, sobretudo a partir do dia 21 de junho de 1951. O próprio delegado da DOPS, responsável pela organização das operações, deixou transparecer isso em seu longo relatório: "a tropa, em dias sucessivos, pode varrer toda a região conflagrada, vistoriando os diversos acampamentos dos bandos e chegando até as barrancas do Rio Paranapanema, sem qualquer resistência e sem qualquer desagradável incidente a lamentar (Arquivo DOPS, pasta n. 599).

Em meados de julho de 1951 já era possível notar a calma e a tranqüilidade em toda a região, com a vida daquelas pessoas voltando ao normal e o trabalho nas roças, nas derrubadas e nas fazendas sendo retomados. Inúmeras pessoas que haviam saído de suas casas, ou com medo da polícia, ou com medo do terror da propaganda contra os posseiros, puderam voltar às suas residências e aos seus afazeres. Mas a história não havia acabado. Por um lado, começava outro processo, o do Inquérito e de julgamento dos "verdadeiros responsáveis pelos acontecimentos locais" (Arquivo DOPS, pasta n. 599) e, de outro, o trabalho da Comissão de Terras e de reassentamento dos posseiros em outras localidades, o que nos permite concluir que o movimento armado contribuiu para que o governo, finalmente, tomasse medidas legais a fim de equacionar o problema da terra dos posseiros na região de Porecatu.

\section{A "última tarefa"}

Com o desmantelamento da resistência armada na região, os delegados da DOPS passaram a realizar o que eles alcunharam de "última parte de nossa tarefa" que era o de apresentar os responsáveis do movimento de posseiros de Porecatu para o julgamento dos tribunais. Assim sendo, no dia 09 de agosto de 1951 concluíram e remeteram para a Vara Criminal do Fórum da Comarca de Porecatu o Inquérito Policial relativo aos movimentos armados dos posseiros de toda a região. Nesse Inquérito foram apontados como responsáveis pelos conflitos, 15 pessoas, entre dirigentes do PCB e camponeses. Os delegados fizeram um verdadeiro "trabalho de seleção" , como eles próprios apontaram, para chegar aos 15 indiciados. O objetivo era criminalizar apenas quem tinha alguma ligação com o PCB ou então havia exercido algum tipo de liderança na organização e direção da revolta. Os indiciados foram os seguintes: 1) Celso Cabral de Mello, o 
"capitão Carlos" , ex-membro da Direção Nacional do PCB, comandante político e estrategista da resistência armada; 2) Arildo Gajardoni, conhecido como "Strogof" , um dos dois principais dirigentes da resistência até a chegada do "capitão Carlos" e, depois, articulador de um dos principais grupos armados na floresta; 3) Hilário Gonçalves Pinha, também conhecido como "Itagiba" , formava com o "capitão Carlos" e "Strogof" o núcleo pensante e articulador das ações armadas na floresta; 4) André Rojo, conhecido como "Panchito", auxiliar do grupo dirigente e espécie de estafeta; 5) "Machado", que fazia a ligação do Comitê de Zona do Partido com o chefe da resistência armada; 6) Newton Câmara ${ }^{14}$, responsável pela retaguarda do movimento armado na cidade, era o presidente da "Comissão de Auxílio aos Resistentes de Porecatu" , cujo objetivo era angariar recursos monetários, alimentos e roupas para os camponeses; 7) Francisco Lourenço Figueiredo, conhecido como "Quiabo" ; 8) Francisco Lourenço Figueiredo Filho, o "Quiabinho", filho de "Quiabo" ; 9) Inocêncio Ferreira Belém, "elemento dado à desordem" , um dos mais ativos do grupo, responsável por inúmeras cenas de violência; 10) Lázaro Bueno de Camargo, vulgo "Lazão", indivíduo "violento, vingativo e turbulento" ; 11) Benedito Bueno de Camargo, vulgo "Coreano" , filho de "Lazão" ; 12) Miguel Gajardoni, irmão de "Strogof" ; 13) João Pernambuco, companheiro de Inocêncio Ferreira Belém em todas as "tropelias" por este chefiadas; 14) Jordão de Tal e 15) Orozimbo de Tal, ambos não identificados, mas "elementos bastante conhecidos em Vila Progresso" .15

Os demais participantes dos grupos armados, mesmo os identificados, não foram incluídos no inquérito policial. Segundo o Delegado Especial da DOPS, Eduardo Louzadas da Rocha, principal responsável pelo inquérito, o motivo da não inclusão se deve ao fato de que "tais elementos foram iludidos por falsas promessas de se tornarem proprietários das terras que ocupassem pela violência e abandonaram os comunistas quando, em virtude da ação policial, passaram a sentir o logro com que Ihes acenaram" (Arquivo DOPS, pasta n. 599).

No entanto, das pessoas indiciadas, apenas Celso Cabral de Mello, o "capitão Carlos" foi preso. Newtom Câmara já havia sido indiciado e preso anteriormente, no processo de Londrina. "Machado" desapareceu e os demais, foragidos, deslocaram-se para outras regiões.

Encerrado o cerco no campo, a "revolta" teve prosseguimento num cenário em que os posseiros jamais estiveram presentes: a Justiça. O principal processo relacionado à luta armada foi dirigido pelo juiz Rafael Rastelli. É interessante notar nesse processo criminal como foram sendo montadas as bases de argumentação e de condenação dos posseiros.

Logo no início do processo, o relatório de apresentação dos inquiridos faz uma apreciação sobre a

${ }^{14}$ Newton Câmara era dirigente do PCB em Londrina e havia sido preso junto com toda a direção e indiciado no processo criminal de Londrina. Como o promotor excluiu-o daquele processo, o delegado do DOPS resolveu incluí-lo no processo criminal de Porecatu.

${ }_{15}$ As informações sobre os 15 acusados foram retiradas tanto do Inquérito Policial como do relatório do Delegado Eduardo Louzadas Rocha, encaminhado ao Coronel Albino Silva, Chefe de Polícia do Estado do Paraná. As alcunhas e os adjetivos são do relatório. As expressões entre aspas também (Arquivo DOPS, pasta n. 599). 
colonização e o rápido povoamento da região Norte do Paraná, procurando definir os agentes sociais que tomaram parte dessa empreitada, principalmente os posseiros. Depois, o juiz faz uma análise dos motivos que levaram os posseiros a resistir em suas posses. Narra ainda as estratégias de resistência utilizadas pelos posseiros, as emboscadas, os tiroteios; descreve minuciosamente as armas utilizadas, para no fim elaborar a sentença final.

A sentença final, proferida em 29 de maio de 1953 jamais foi executada. Celso Cabral de Mello, o "capitão Carlos", por exemplo, foi condenado a 14 anos de prisão, que deveria cumprir na Penitenciária Central do Estado. Mas depois que delatou os companheiros e fugiu da cadeia de Porecatu, jamais foi encontrado. Um dos comandantes máximo do movimento, Arildo Gajardoni, o "Strogoff" foi condenado a sete anos de prisão. Também nunca foi localizado. Em depoimento no final dos anos 1990, Hilário Gonçalves Pinha afirma que Arildo Gajardoni foi para Goiás, onde se envolveu no movimento de Trombas e Formoso e que lá, em confronto com a polícia, acabou sendo morto (PINHA, 1999). Já Hilário Gonçalves Pinha, o "Itagiba" , foi condenado a nove anos de prisão, chegou a recorrer ao Supremo Tribunal, mas antes da decisão final, que o absolveu, já havia caído na clandestinidade, indo trabalhar na organização de sindicatos de trabalhadores rurais no Estado de São Paulo.

Os demais enquadrados no processo foram Inocêncio Ferreira Belém, Francisco Lourenço Figueiredo, Francisco Lourenço Figueiredo Filho, André Rojo, Lázaro Bueno de Camargo, Orozimbo Vieira, Benedito Bueno de Camargo e Miguel Gajardoni. A eles o juiz Rafael Rastelli dedicou um longo parágrafo na sentença:

Por serem simples participantes de grupos armados, homens rudes, semi analfabetos que se deixaram iludir pela dialética dos chefes, mas que por atos espontâneos, foram tutores de violências e atrocidades, em conseqüência das atividades dos bandos armados, dos resistentes de Porecatu, condeno-os a pena de três anos de prisão a serem cumpridos na Penitenciária Central do Estado (Arquivo DOPS, pasta n. 599).

Mas também nesse caso ninguém foi encontrado e preso. Três outros resistentes foram absolvidos porque não foram devidamente identificados: João Pernambuco, Machado e Jordão de Tal.

Terminava assim um dos mais importantes conflitos de terras do Estado do Paraná. Para os latifundiários, o gosto da vitória. Para a polícia, o do dever cumprido. E os posseiros? Bem, alguns deles se fixaram na terra, outros migraram para distantes regiões do Estado, outros ainda, rumaram para a militância política, sobretudo no Partido Comunista; mas os seus rostos podem ser vistos ainda hoje, numa luta constante pela terra e pela reforma agrária. Como ao longo de todo o século XX. 


\section{Considerações finais}

A polícia política (os temidos DOPS) povoa o imaginário da população em geral, com notícias de agentes infiltrados, delações, prisões, torturas. Para aquela parcela da população que sofreu os efeitos de sua ação, muitas vezes fica a imagem de um órgão eficiente e inexorável.

Para a historiografia, sedimentou-se a ideia de que a polícia política era o local da repressão e de combate aos "inimigos" do regime. O que não deixa de ser verdade. Mas para entender a polícia não basta apenas isso. É preciso ir mais longe. É necessário adentrar nos seus meandros e tecer as tramas de sua própria história. Ao analisar o interior da DOPS, desde os procedimentos legais de sua constituição, o aparelhamento do órgão com armas, materiais e equipamentos, a montagem de redes de informação, a relação com outros órgãos assemelhados, no país e no exterior, entre outros tantos temas, verifica-se que o órgão tinha imensas dificuldades de realizar o seu trabalho e que, muitas vezes, era suscetível a erros e procedimentos ineficientes.

Evidentemente que esse universo de questões é possível de ser problematizado, principalmente a partir da abertura dos arquivos da DOPS. O material produzido e recolhido pelo órgão permite aos pesquisadores tomar contato com o poder do aparato policial, desvendando o seu trabalho e desnudando os pensamentos e ações daqueles que conceberam, organizaram e executaram o trabalho de segurança e de defesa da ordem política e social. Foi esse o sentido desse pequeno artigo.

\section{Referências}

ADUM, Sônia Maria Sperandio Lopes. A subversão no paraíso: o comunismo em Londrina (19451951). 2003. 267 f. Tese (Doutorado em História Social) - Universidade de São Paulo, São Paulo.

AMANCIO, Silvia Maria. Ontem, luta pela terra; hoje, monumento histórico: a revolta dos posseiros no Sudoeste do Paraná em suas variadas versões. 2009. 178 f. Dissertação (Mestrado em História) - Universidade Estadual de Maringá, Maringá.

ALVES, Paulo. $A$ verdade da repressão: práticas penais e outras estratégias na ordem republicana (1890-1921). São Paulo: Arte \& Ciência, 1997.

CORREA, Manoel Jacinto. Entrevista concedida ao Centro de Pesquisa e Documentação em História da UEL. Londrina, 1983.

FELISMINO, Tadeu. A guerra de Porecatu: a história do movimento armado pela posse da terra 
que sacudiu o Norte do Paraná. Folha de Londrina, Londrina, 28 jul. 1985.

IOKOI, Zilda. Marcia Gricoli. Igreja e camponeses. teologia da libertação e movimentos sociais no campo. São Paulo: Hucitec, 1996.

MARTINS, José Souza. Caminhada no chão da noite. emancipação política e libertação nos movimentos sociais no campo. São Paulo: Hucitec, 1989.

Os camponeses e a política no Brasil. 2. ed. Petrópolis: Vozes, 1983.

O' DWYER, Eliane. Cantarino. Da proletarização renovada à reinvenção do campesinato. 1988. Tese (Doutorado em Antropologia Social) - PPGAS. Museu Nacional. Rio de Janeiro.

OIKAWA, Marcelo. Porecatu: a guerrilha que os comunistas esqueceram. São Paulo: Expressão Popular, 2011.

PINHA, Hilário Gonçalves. Entrevista concedida a Ângelo Priori. Porto Alegre, 7 out. 1999.

PRIORI, Angelo. Legislação social trabalhista: a exclusão do trabalhador rural. História. São Paulo, v. 15, p. 287-302, 1996a.

O levante dos posseiros: a revolta camponesa de Porecatu e a ação do Partido Comunista Brasileiro no campo. Maringá: Eduem, 2011.

O protesto do trabalho: história das lutas sociais dos trabalhadores rurais do Paraná (19541964). Maringá: Eduem, 1996b.

ROLIM, Rivail Carvalho. O policiamento e a ordem: histórias da polícia em Londrina (1948-1962). 3. ed. Londrina: Ed. da UEL/SEED/PR, 2008.

SIGAUD, Ligia. Os clandestinos e os direitos. São Paulo: Duas cidades, 1979.

SILVA, Osvaldo Heller. A foice e a cruz. comunistas e católicos no sindicalismo dos trabalhadores rurais do Paraná. Curitiba: Rosa de Bassi, 2006.

TONELA, Celene; VILLALOBOS, Jorge; DIAS, Reginaldo. As memórias do sindicalista José Rodrigues dos Santos: a luta dos trabalhadores rurais do Paraná. Maringá: Eduem, 1999. 